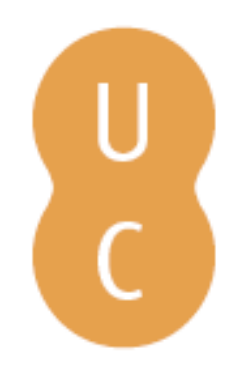

\title{
pompalina
}

\section{Camões e D. Francisco de Portugal}
Autor(es): $\quad$ Cirurgião, António
Publicado por: Imprensa da Universidade de Coimbra
URL
persistente:
URI:http://hdl.handle.net/10316.2/31192
DOI:
DOI:http://dx.doi.org/10.14195/978-989-26-0569-2_32

Accessed : $\quad$ 26-Apr-2023 10:56:00

A navegação consulta e descarregamento dos títulos inseridos nas Bibliotecas Digitais UC Digitalis, UC Pombalina e UC Impactum, pressupõem a aceitação plena e sem reservas dos Termos e Condições de Uso destas Bibliotecas Digitais, disponíveis em https://digitalis.uc.pt/pt-pt/termos.

Conforme exposto nos referidos Termos e Condições de Uso, o descarregamento de títulos de acesso restrito requer uma licença válida de autorização devendo o utilizador aceder ao(s) documento(s) a partir de um endereço de IP da instituição detentora da supramencionada licença.

Ao utilizador é apenas permitido o descarregamento para uso pessoal, pelo que o emprego do(s) título(s) descarregado(s) para outro fim, designadamente comercial, carece de autorização do respetivo autor ou editor da obra.

Na medida em que todas as obras da UC Digitalis se encontram protegidas pelo Código do Direito de Autor e Direitos Conexos e demais legislação aplicável, toda a cópia, parcial ou total, deste documento, nos casos em que é legalmente admitida, deverá conter ou fazer-se acompanhar por este aviso.

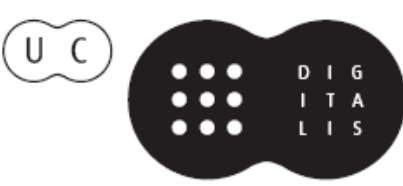




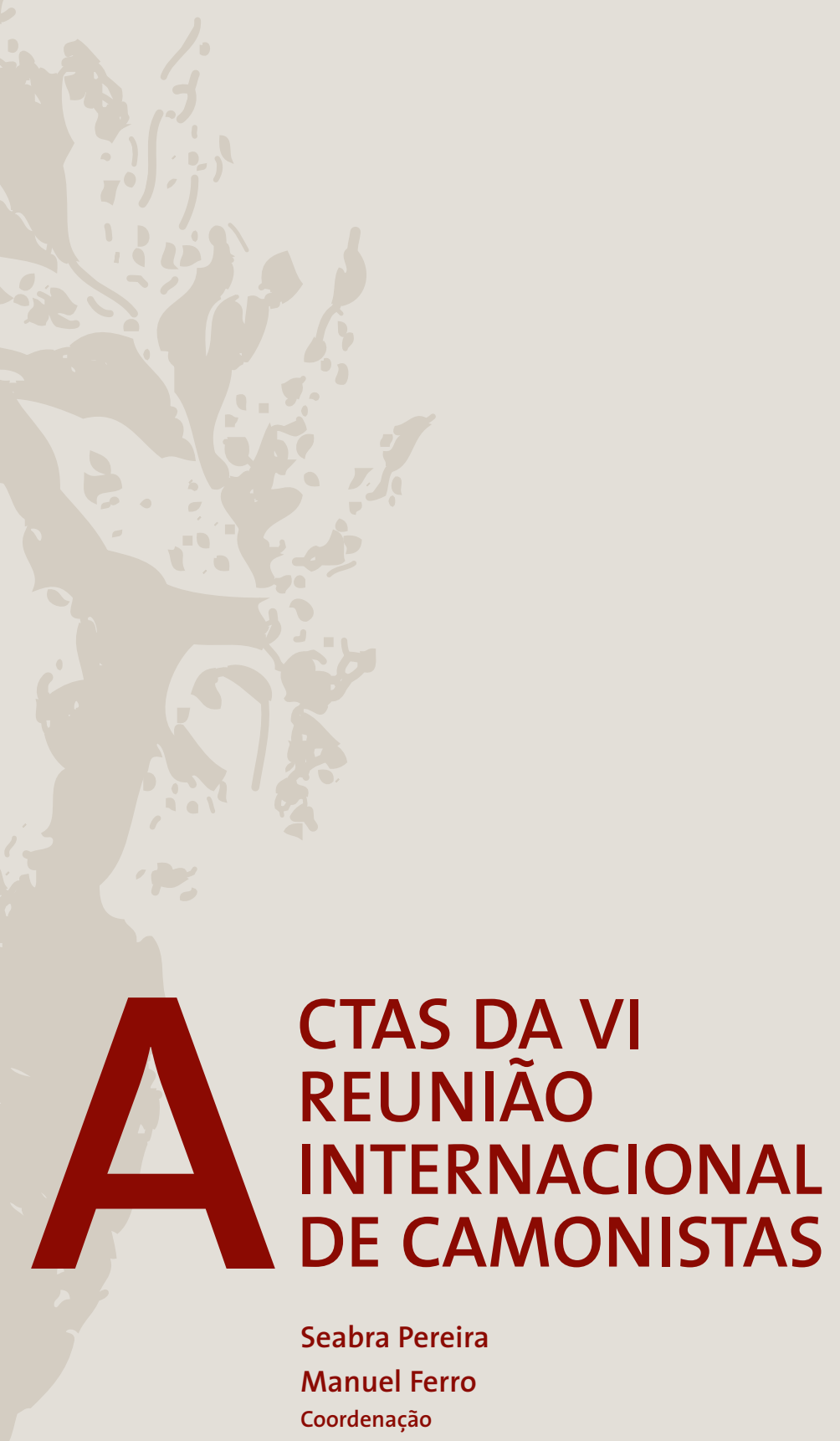




\section{António Cirurgiáo \\ University of Connecticut}

\section{CAMÓES E D. FRANCISCO DE PORTUGAL}

"Eu vos direi o que me sucedeu com o vosso galante D. António de Mendonça, e meu também, segundo o muito que foi meu amigo. Mostrei-lhe eu, antes que ele de todo me soubesse as manhas, de que já suspeitava, aquele soneto que anda nas minhas obras, escrito ao Príncipe de Espanha, e começa: «No te ofrece aquel triunfo, oy solamente.» Viu-o, e olhou-me; e, depois de mostrar que folgava de o ver, me disse: "- Yo pensé hasta ahora que de presente no se hallaba otro poeta en su tierra sino D. Francisco de Portugal». Ao que eu respondi: " - Yo también soy D. Francisco, y soy de Portugal.» Tanta opiniâo lhe deram os estranhos, quanta quiça agora lhe nega a pátria, ou lhe regatea."

D. Francisco Manuel de Melo, Apólogos Dialogais, "Hospital das Letras".

"Ouve-se, umas vezes bem nítido, outras mais esbatido, o diálogo que com a poesia camoniana travam poemas de autores vários, de Rodrigues Lobo a D. Francisco Manuel de Melo, de Veiga Tagarro a Barbosa Bacelar, de Faria e Sousa a Leitão Ferreira. Mas o estudo sistemático da presença de Camóes na poesia portuguesa de Seiscentos é trabalho por fazer."

Maria Lucília Gonçalves Pires, A crítica camoniana no século XVII.

E como "o estudo sistemático da presença de Camóes na poesia portuguesa de Seiscentos é trabalho por fazer", resolvemos aproveitar esta "VI Reunião Internacional de Camonistas" para dar o nosso modesto contributo a fim de ajudar a preencher mais esta lacuna das letras portuguesas do século XVII.

D. Francisco de Portugal (nascido em Lisboa em 1585, e morto na mesma cidade em 1632) é um daqueles autores que muitos citam mas que poucos lêem. E das duas obras que dele se conhecem - Divinos e Humanos Versos (1652), compilados pelo seu filho D. Lucas de Portugal e dedicados ao Príncipe Dom Teodósio, e A Arte de Galanteria (1670), ambas de publicação póstuma, como se vê - é Arte de Galanteria a mais frequentemente referida pelos estudiosos, em virtude do notável impacto que teve na praxe da corte e da sua semelhança com Il Cortegiano de Castiglione.

De facto, a julgar pelo testemunho de vários estudiosos, A Arte de Galanteria tornou-se uma espécie de vademecum dos candidatos a cortesão e o seu autor o cortesão prototípico: «As partes naturaes, que nelle concorrião, \& as adquiridas, com hum 
particular genio que teve para o trato da Corte, \& das Damas, o fizerão hum dos mais applaudidos, o estimados Cortesãos de nossa idade: nem houve algum de maior opinião na Corte delRey de Castella Dom Felipe Terceiro" ${ }^{1}$.

Pelo que se refere à sua biografia, pode dizer-se que D. Francisco de Portugal, em comparação com a maioria dos seus contemporâneos, foi bastante afortunado, se tivermos em conta o que Francisco Luís de Vasconcelos, seu primeiro biógrafo, sobre ele escreveu, na longa "Memória» que precede a primeira e única edição de seus Divinos e Humanos Versos, o rasgado encómio que Jacinto Cordeiro lhe faz no Elogio de Poetas Lusitanos $(1631)^{2}$, as consideraçóes que sobre ele tece D. Francisco Manuel de Melo no seu "Hospital das Letras", pela boca das quatro personagens intervenientes no diálogo (o Autor, Quevedo, Lípsio e Bocalino) ${ }^{3}$, as duas páginas e meia que Teófilo Braga lhe dedica na sua História da Literatura Portuguesa ${ }^{4}$, e ainda os comentários que Joaquim Ferreira faz no prefácio à tradução portuguesa de Arte de Galantaria 5 .

Além de homem da corte, sobretudo no reinado de Felipe III de Espanha e II de Portugal, corte que ele abrilhantou como ninguém, a julgar pelo testemunho de seus contemporâneos e pelo dele próprio, este ilustre fidalgo da Casa dos Condes de Vimioso foi também homem de acção castrense, distinguido-se no comando das armadas da Índia e do Brasil, realizando assim nele próprio o ideal do perfeito cidadão, segundo o credo cívico da época: excelente nas armas e nas letras: "Não é falta de modéstia referir eu as abonaçóes alheias para a própria. E bem se pode admitir que faça comentários de cortesáo quem os pudera fazer de marcial, pois eu fui soldado sempre por profissão» - declara D. Francisco de Portugal na sua Arte de Galantaria ${ }^{\text {. Como diz }}$

${ }^{1}$ Ao Principe / D. Theodosio / Nosso Senhor. / Divinos, e Hvmanos / Versos, / de / Dom Francisco / de Portugal, / por D. Lvcas de Portugal / seu filho, Commendador da villa de Fronteira, / Mestresala de Sua Magestade. / Lisboa. / Officina Craesbeckiana. / Anno 1652. (p. 3).

2 "Discreto Don Francisco, sigo en tanto,

Portugal sin igual, cuyo sentido

para la elevación, moviendo á espanto

el ingenio mas alto, y presumido:

imitar presumi su heroico canto,

que imposible me fué, quede vencido,

Icaro quise ser de tal sujeto,

que no puede imitarse lo discreto."

Jacinto Cordeiro, "Elogio de poetas lusitanos", apud Andre Froes, Amores Divinos (Lisboa, 1631). Noticia bibliográfica por Antonio Pérez Gómez. Valencia: Duque y Marqués, 1959, p. 110.

${ }^{3}$ D. Francisco Manuel de Melo, Apólogos Dialogais - Escritório Avarento [,] Hospital das Letras. Vol. II. Prefácios e Notas do Prof. José Pereira Tavares (Lisboa: Editora Sá da Costa, 1956), pp. 171-174.

${ }^{4}$ Teófilo Braga, História da Literatura Portuguesa - III - Os Seiscentistas (Porto: Livraria Chardron, de Lello \& Irmão, 1916), pp. 487-489.

Para mais dados sobre a biobibliografia de D. Francisco de Portugal, veja-se, por exemplo, Carlos Alberto Ferreira, Biblos, Vol. XXII, 1947, e Massaud Moisés, Pequeno Dicionário de Literatura Portuguesa (São Paulo: Cultrix, 1981), p. 299.

5 D. Francisco de Portugal, Arte de Galantaria. Adaptação, prefácio e notas por Joaquim Ferreira. (Porto: Editora Domingos Barreira, 1943).

${ }^{6} I d .$, Ib., p. 140. 
o seu biógrafo, D. Francisco de Portugal «Gastou os primeiros anos no estudo das artes liberaes, \& no exercício das armas, \& cavallarias."?.

E foi no contexto da sua carreira de homem de armas que tiveram origem as duas obras de que vamos servir-nos para documentar a presença de Camóes em mais um autor português do século XVII.

Perseguido por se haver recusado a ir à Índia "por Capitão-Mor das Naus», "sabendo que nas naus iam ordens contra o Vice-Rei que então governava a India, que era seu parente chegado, e grande amigo", e "preso em hua torre [que tudo leva a crer tenha sido a Torre de Belém] por não querer ir á India de Capitão mór em anno de Viso_Rey, parecendolhe que sendo jà em tudo tão crescido, lhe náo convinha ir com nome de Capitão mor, levando bandeira de Almirante», como declara o seu biógrafo na página 7 da "Memória...» anteposta a Divinos e Humanos Versos, D. Francisco de Portugal encontrou lenitivo para as suas penas de prisioneiro no exercício das letras. E, «tomando ora la espada, ora la pluma», à imitação de Garcilaso e de Camóes, por exemplo, como ele próprio nos informa na "Carta a um Amigo» (p. 41), foi também no exercício das letras que ele encontrou alívio para as suas agruras e para as suas mágoas amorosas quando se viu obrigado a lutar com o mar em tempestade durante uma das várias viagens marítimas a que teve de se aventurar, contra a sua vontade: "Com esta dor me sahi pella barra Capitáo contra mim; que a selo dos exercitos de Xerxes o fora de mais desditas que soldados» (p. 38).

E foi assim que D. Francisco de Portugal nos pôde legar "Prisōes e solturas de uma alma" e duas "Cartas", publicadas à guisa de apêndice a Divinos e Humanos Versos. E foi assim que mais um escritor do século XVII recorreu a Camóes para melhor ilustrar a mensagem com que se propôs brindar os seus leitores: uma mensagem em que os dados autobiográficos vão adornados com versos de poetas alheios - estrangeiros e nacionais - entre os quais sobressai Camóes ${ }^{8}$.

\footnotetext{
${ }^{7}$ Divinos e Humanos Versos (p. 2)

8 Convém informar que D. Francisco de Portugal também citou Camóes para ilustrar três aspectos da sua Arte de Galanteria.

Vejamos esses versos, pela ordem em que aparecem na obra, pp. 43, 52 e 164, respectivamente, da ed. referida na nota 5:

"Chamam-lhe fado mau, fortuna escura,

Sendo só providência de Deus pura” (Os Lus., X, 38).

"Entre as damas gentis da corte inglesa

E nobres cortesãos, acaso um dia

Se levantou discórdia, em ira acesa

(Ou foi opiniẫo, ou foi porfia).

Os cortesãos, a quem tão pouco pesa

Soltar palavras graves de ousadia,

Dizem que provarão que honras e famas

Em tais damas não há para ser damas" (Os Lus., VI, 44).

"Não faltarão cristãos atrevimentos

Nesta pequena Casa Lusitana” (Os Lus., VII, 14).

Em nenhum destes três casos, se menciona Camóes pelo nome. Na primeira citação, D. Francisco de Portugal atribui os versos ao "nosso Poeta"; na segunda ao "nosso grande Poeta"; e na terceira, não faz qualquer referência ao autor citado.
} 
Tanto nas "Prisóes", em língua portuguesa, como nas "Cartas", a primeira em língua portuguesa e a segunda em língua castelhana, escritas em prosa e em poesia, existe uma grande abundância de citaçôes de autores portugueses, espanhóis e italianos, sobretudo em poesia. Mas é curioso notar que, com excepção de Francisco de Sá de Miranda, nomeado especificamente duas vezes (pp. 38 e 42), e Ovídio (p. 41), Jorge Manrique (p. 41), Petrarca (p. 39), Don Diego de Mendonza (p. 45) e Don Thomas de Carrillo (p. 48), nomeados uma vez cada um, só Camóes, o autor mais vezes referido, é devidamente elogiado como homem de armas e como homem de letras, no contexto de alguns dos versos que dele cita, como se com isso D. Francisco de Portugal nos quisesse dizer que Camóes era uma estrela de primeira grandeza no meio da constelação dos poetas que adornavam o céu de Portugal e o céu de outras naçôes ${ }^{9}$. E como se com esse procedimento nos quisesse dizer também que, entre as muitas maneiras de honrar o Príncipe dos Poetas do seu tempo, como um parente seu (D. Gonçalo Coutinho) tinha feito, ao inscrever essas palavras numa modesta lápide que lhe colocara sobre o túmulo, era cultivar um género literário que Camóes pusera em voga - as Cartas meio sérias e meio jocosas e burlescas - e servir-se dos seus versos para tornar essas cartas mais vivas, mais atraentes e mais ricas em conteúdo.

Neste estudo vamos procurar inventariar todas as citaçóes de Camóes nas obras referidas de D. Francisco de Portugal e enquadrá-las no respectivo contexto, para, dessa maneira, verificarmos até que ponto Camóes, elevado a autoridade literária, ao mais alto nível, ao lado dos dois gigantes da antiguidade clássica - Homero e Virgílio - se tornou para D. Francisco de Portugal, como se tornara para outros escritores, ponto de referência e de ilustração dos mais variados conceitos psicológicos, filosóficos e morais ${ }^{10}$. Umas vezes nomeando-o expressamente e citando-o com o maior rigor, outras vezes deixando ao leitor a oportunidade de detectar ele próprio as breves passagens que dele cita, a verdade é que D. Francisco de Portugal aproveita as mais diversas ocasióes para apoiar e ilustrar a sua causa com o exemplo de Camóes.

\footnotetext{
${ }^{9}$ Francisco de Sá de Miranda é designado uma vez por Francisco de Sá, logo nas primeiras duas linhas da “Carta a um Amigo” (p. 38), e uma outra vez simplesmente como Sá (p. 42 da mesma Carta).

Entretanto, D. Francisco de Portugal transcreve versos de Sá de Miranda mais quatro vezes: pp. 8 e 9. Esses versos pertencem todos à famosa "Carta a D. João III" (pp. 32, 36 e 39).

Ei-los, pela ordem em que se encontram em «Prisóes e Solturas de uma Alma»:

"A tempo o bom Rey perdoa,

a tempo o ferro he mezinha” (p. 8).

"Fazse engano ás leys da terra,

nunca se faz ás do Ceo" (p. 9).

"A vida desaparece,

entretanto geme \& jaz

o que cahio" (p. 9).

"Suspirão, não podem mais;

Y ás vezes não muito claro” (p. 9).

${ }^{10}$ Note-se que entre as poesias compiladas pelo seu filho, D. Lucas de Portugal, se encontra um romance (o n. ${ }^{\circ}$ XXI) de 68 versos em que D. Francisco de Portugal parafraseia a famosa cantiga de Camóes: "Leonor vai pera a fonte" (pp. 78-79).

Aguiar e Silva transcreve parte deste romance numa nota à sua obra Maneirismo e Barroco na Poesia Lírica Portuguesa (Coimbra: Imprensa da Universidade, 1971), p. 437.
} 
Antes de prosseguir, duas coisas se impóe esclarecer: primeiro, que é possível que, além dos excertos de Camóes aqui inventariados, outros existam na obra que lhe pertencem também, mas que não foi possível atribuir-lhe, não só por continuar por estabelecer o cânone da lírica camoniana, mas também por ainda não dispormos de uma concordância para a lírica que dele se conhece, idêntica à que existe para Os Lusíadas $^{11}$; segundo, que os excertos vão ser referidos pela ordem em que se encontram na obra.

Para demonstrar a injustiça de que era alvo, ao ter que penar inocente, entre as grades de uma prisão, que, como já se disse, tudo leva a crer tenha sido a Torre de Belém, a julgar pelo contexto ${ }^{12}$, D. Francisco de Portugal desabafa assim:

"Quem vio nunca representar tão lastimosas nouidades, perdição tão miserauel? A quem as inclemencias do mar offerecerão mais barbaros perigos, na Sytia fria, ou na Lybia ardente [Os Lusíadas, III, 128)? Que theatro de lastimas deixou ás memorias humanas aquelle occulto, \& grande Cabo [Os Lusíadas, V, 50], como experimento nestas paredes, cuyos pedaços aun lloran las desdichas de sus daños? Que he mais brauo mar o de hua semrazão, vento mais tempestuoso de hua enueja, que se encerrão num odio, outra Cafraria, \& numa tyrania, outros Acroceranios infamados (Os Lusíadas, VI, 82)?”

Aqui temos nós três passagens de Os Lusíadas utilizadas pelo autor para referir e enfatizar as injustiças de que se crê vítima inocente. No primeiro caso é uma alusão àquela passagem em que Inês de Castro implora ao Rei D. Afonso IV que a sujeitem aos mais inauditos castigos, metaforizados pelo frio polar da Scítia e pelo calor tropical da Líbia, contanto que lhe preservem a vida para se poder dedicar à felicidade e bemestar do seu Príncipe e dos seus filhos. No segundo, refere-se o autor aos indescritíveis actos de vingança que o Gigante Adamastor infligiu aos portugueses que ousaram desafiar a sua soberania sobre os mares. No terceiro caso, o autor evoca a oração que Vasco da Gama dirigiu à "Divina guarda, angélica, celeste», quando, já perto do fim da sua demanda, quase à beira da Índia, corria o risco iminente de ser tragado, ele e os seus, pelo «mar até o inferno aberto». Deu-se isto por ocasião da majestosa e dantesca Tempestade Marítima, topos quase obrigatório de todos os poemas épicos.

A próxima evocação de Camóes, a quem o autor nomeia expressamente, surge a seguir à recitação de um romance sobre os amores adulterinos do Rei D. Fernando de Portugal e de D. Leonor Teles. Conhecedor profundo de Os Lusíadas, o autor recorre a Camóes para absolver D. Fernando desse pecado que os seus contemporâneos e os vindouros lhe não perdoaram, transcrevendo os últimos quatro versos da oitava 143 do Canto III:

${ }^{11}$ Chama-se ainda a atenção para a dificuldade que há em inventariar todos os versos de Camões, devido também ao facto de ainda náo dispormos do dito cânone da poesia lírica (embora se saiba a priori que o cânone perfeito nunca poderá existir).

12 A passagem de "Prisóes e Solturas de uma Alma" que melhor parece apontar para que o lugar da prisão do autor seja a Torre de Belém é a seguinte:

"Neste Castello, cuja fundação ordenou hum amor desordenado, não sem misterio derão comigo nelle á costa as naos da índia para que vejão suas ruinas no mais fiel amante o amor mais fundado em entendimento" (p. 9). 
"Logo affectuosamente aquelle grande Mestre dos Poetas Epicos o ampara com as proprias fraquezas, que são sempre as forças de amor.

Desculpado por certo está Fernando, para quem tem de amor experiencia. Mas antes tendo liure a fantesia, por muito mais culpado o julgaria.

Mais desculpado estiuera se vós foreis a causa, mal bosquejada nestes pinceis heroicos, que he tamanha cousa vossa, que vos offendem os merecimentos por limitados, \& só vos pódem luzir as verdades por sem limite” (p. 12).

Note-se que o autor, ao mesmo tempo que se apoia na autoridade de Camóes para justificar os amores adulterinos (estaria ele ou o destinatário da sua missiva também numa situação análoga à do Rei D. Fernando?), aproveita o ensejo para enaltecer a excelência de Camóes como poeta épico, chamando-lhe "Mestre dos Poetas Épicos», numa altura em que não faltava quem lhe recusasse esses predicados, como vários camonistas nos têm mostrado.

A fim de matar o tempo, durante os longos dias de encarceramento, o autor espraia os olhos lá por "adonde el Tajo parece ni bien rio, ni bien mar», e "topando já fontes nas grandezas de Belem», exclama:

"Que muito que tornem ás suas aréas aquelle antigo nome de praya de lagrimas? Dalli se espanta a vista naquella immensidade de edificios, emula dos Reynos; por quem disse o nosso Camóes.

E tu nobre Lisboa, que no mundo

facilmente das outras es Princesa,

que edificada foste do facundo

Ulysses, por quem foi Dardania acesa" (p. 18).

Trata-se daquela passagem de Os Lusíadas (III, 47) em que Vasco da Gama narra ao Rei de Melinde a pré-história e a história de Portugal. O que quer dizer que, por trás das grades de uma prisão, D. Francisco de Portugal tem olhos para contemplar aquela cidade de "mármore e de granito» que Herculano também viria a cantar dois séculos e tal mais tarde, assim como para evocar "aquelle antigo nome de praya de lagrimas», que é certamente a de Belém, aquela de onde saíam as armadas, a começar pela de Vasco da Gama, em demanda dos «mares nunca dantes navegados» e das terras desconhecidas.

Preso injustamente, em sua opinião, o autor, da mesma maneira que Bocage faria mais tarde ${ }^{13}$, pensa que, tal como a ele, igual fado coubera ao príncipe dos poetas portugueses, segundo o testemunho que ele próprio nos dá não só na poesia lírica, mas também na épica. E assim se explica que D. Francisco de Portugal evoque aquela

13 Veja-se o soneto que começa: «Camóes, grande Camões, quão semelhante...». 
passagem de Os Lusíadas (X, 128), em que Camões se queixa amargamente das injustiças de que foi vítima. E, ao mesmo tempo que usa o homem como exemplo eloquente de uma injustiça que se tornaria emblemática, mais uma vez aproveita a ocasião para tecer os mais rasgados elogios ao Poeta: "Que disse desigual engenho, mas em igual fortuna, verseha o injusto mando executado", "Naquelle, cuja lira sonorosa / Serà mais afamada, que ditosa» (p. 23, a qual, por gralha tipográfica, aparece como 22).

A braços com toda a espécie de contratempos e desventuras, degladiando-se sem quartel uns com os outros, o autor vê "A cada passo vn nuevo pensamiento" "en la Babylonia de mi vida», não lhe restando outro remédio senão ocupar a mente em «memorias de Sion perdida». E é ao encontrar-se nesse deplorável estado que lhe vêm à mente aquelas palavras com que Camôes evoca magoado, na oitava final do Canto I de Os Lusíadas, as indizíveis traiçôes de que Vasco da Gama é objecto às mãos daqueles que se haviam mostrado ser seus amigos:

"No mar tanta tormenta, \& tanto dano,

Tantas vezes a morte apercebida,

Na terra, tanta guerra, tanto engano,

Tanta necessidade auorrecida:

Onde pode acolherse hum fraco humano,

Onde terà segura a curta vida?

Que não se arme, \& se indigne o Ceo sereno

Contra hum bicho da terra tam pequeno" (I, 106).

Desta oitava, D. Francisco de Portugal limita-se a transcrever apenas o quinto verso, e ainda esse com uma pequena variante: «as que estado há sem desacertos? Onde se póde acolher hum vil humano, que não encontre desgostos? Não há buraco no mundo para escapar do mundo, senáo Deos, só quem o busca se faz senhor de tudo» (p. 24) ${ }^{14}$. Note-se também que, em vez de se queixar do próprio Deus, como faz Camóes, na peugada de Job, D. Francisco de Portugal, fazendo uma leitura livre da oitava de Camóes, encontra barrocamente em Deus o único refúgio para «um vil humano» condenado a viver num mundo fértil em «desacertos» e «desgostos.» Esquecido momentaneamente das suas próprias dores, o autor, imitando o Camóes moralista e poeta cívico, volta o olhar perplexo e preocupado para o estado lastimável em que a pátria jaz imersa, fazendo-se eco de um motivo literário tão tristemente caro aos seus contemporâneos, apresentado sob as roupagens do topos do Ubi sunt:

"Tudo desajuda esta despedaçada patria; mas se os filhos lhe virão as costas, que muito que lhas virem os fados? [...]. Sempre ocasionárão grandes ruínas nouidades no gouerno tão defendidas dos mais sãos legisladores; aquellas mossas

\footnotetext{
${ }^{14}$ Contra os que possam pensar que estamos perante casos de plagiato, um pouco à imitação do que fez Miguel Leitão de Andrada na sua Miscelânea, argumentaremos com o próprio Camôes, o qual não só cita, sem os mencionar expressamente, autores alheios na sua poesia, e principalmente nas suas Cartas, idênticas, na sua estrutura externa, a estas de D. Francisco de Portugal, como já se referiu por alto.

Essas cartas de Camóes estão recheadas de versos de poetas alheios, alguns possivelmente ainda por identificar.
} 
de pao, por onde os nossos velhos gouernauão com aquella santa inteireza, rosto ao sim, \& rosto ao não: erão bons, erão honrados. [...] Hoje quem menos anda do que se deue, mayores pagas se lhe dão [...].

Leys em fauor do Rey se estabelecem, as em fauor do pouo só perecem” (p. 28) ${ }^{15}$.

Na segunda "Carta a um Amigo", escrita no "Galeão S. Luis» e datada de 20 de Setembro de 1620 (p. 44), o autor começa por dirigir uma catilinária contra o casamento, dizendo:

"Em fim, na minha opinião, mar, casamento, \& quaresma são ua mesma cousa. Folgue V. M. de se ver longe dellas: que brincos que obrigão a confissão muito deuem ter de morte, aquelle imperio de ua Dama, aquelle ser, aquelles não sei ques, tão divinos como respeitados,

Perdeislo todo como sois casadas, passaisuos de señoras a cautiuas.

Disse o outro. Eu deixando esta materia perigosa, digo tudo nestas palavras:

O que noiva que lá fica!

O que inueja que là vem!” (p. 38).

No último Canto de Os Lusíadas (X, 120), o poeta, depois de ter censurado os que se crê serem os Jesuítas por se deixarem ficar na pátria, em vez de irem pregar a lei de Cristo para as novas terras descobertas pelos portugueses, lá no Oriente distante, resolve arrepiar caminho, ao dar-se conta de que está a enveredar por sendas escabrosas: "Mas passo esta materia perigosa / E tornemos a costa debuxada.»

Dizer que, meio a sério meio a brincar, D. Francisco de Portugal se deve ter sentido na pele de Camóes, ao vituperar o sacramento do matrimónio, cremos ser desnecessário, tendo em conta também, a julgar pelas outras citaçóes, de que ele conhecia muito bem a obra de Camóes, para transcrever simples pedaços de versos ${ }^{16}$.

${ }^{15}$ Em certo aspecto talvez se pudesse dizer que mais que o recurso a Camóes para ilustrar os conceitos dele, estamos antes perante um caso em que D. Francisco de Portugal ilustra com o seu texto uma série de princípios morais disseminados por Camóes nos cantos de Os Lusíadas. Pelo que se pode concluir que é o Camôes moralista o que mais apelo tem para com o autor, o que concorre admiravelmente para definir a estrutura essencial das suas Cartas.

Esta passagem de D. Francisco de Portugal traz-nos à mente a famosa carta de Francisco de Sá de Miranda ao Rei D. João III, expressamente citada pelo autor seiscentista, como se verificou anteriormente.

16 Vários têm sido os estudiosos de Camóes que têm chamado a atenção para os aspectos da sua obra que mais têm sido usados para imitação, paráfrases, centôes, paródias, etc. Veja-se, a título de exemplo, o que se escreveu sobre a projecção dos sonetos "Alma minha gentil que te partiste», "Sete anos de pastor Jacob servia», para já não falar das redondilhas «Sobre os rios que vão.»

Sobre este aspecto, vejam-se, por exemplo, Edward Glaser, Maria de Lourdes Belchior, Ana Hatherly. 
Como a segunda carta trata sobretudo de amor, logo na segunda página o autor cita novamente Camóes (e mais uma vez Os Lusíadas) a respeito do império que o amor, desta vez sob a forma de Vénus, exerce sobre os corações humanos:

"E se ouuer quem lhe pareça que os espiritos, em cujos nomes vão estas perguntas, por serem de peixe, não terão lugar senão na queresma: V. M. lhe responda, que Venus nasceo das escumas do mar, \& que o fogo de Amor crece mais entre contrarios, \& o mesmo effeito faz nas agoas, que nas almas, \& deste galante a este proposito disse o nosso Camóes.

Mal auerá na terra quem se guarde,

Se teu fogo immortal nas agoas arde" (p. 39).

Como se vê claramente, estamos perante aquela passagem da Ilha dos Amores (IX, 42) em que Vénus ordena ao seu filho Cupido que faça ver aos homens quanto o amor é belo, sublime e necessário para que os que são chamados à realização de empresas marítimas sejam verdadeiros modelos de beleza varonil e de virtude heróica, distinguindo-se assim de todos aqueles que voltam as costas ao mandamento do amor virtuoso ou honesto, como então se dizia, dentro dos princípios doutrinários de tradição platónica:

"Quero que aja no reyno Neptunino

Onde eu naci, progenie forte $\&$ bella,

E tome exemplo o mundo vil, malino,

Que contra tua potencia se reuela,

Porque entendão que muro Adamantino,

Nem triste hypocrisia val contra ella.

Mal aueverá na terra quem se guarde,

Se teu fogo imortal nas agoas arde."

Forçado a experimentar toda a sorte de aventuras inerentes às viagens marítimas, como aquela em que se encontra, de quem se havia de socorrer o autor senáo de Camóes, sabendo que o mar está omni-presente no poema épico do autor tantas vezes evocado?

"Mas tudo isto he porque se quer igualar el que duerme, al que no duerme. Não há Comendas com que se pague, não digo eu hua tormenta, senão ua bonança. Veja V.M. se lhe representa bem o Camóes nestes versos que já passou nesta má vida.

Vigiando, \& vestindo o forjado aço, sofrendo tempestades, \& ondas cruas, vencendo os torpes frios no regaço do Sul, \& regióes de abrigo nuas, engolindo o corruto mantimento temperado c'o arduo sofrimento." 
Trata-se, como se sabe, dos últimos seis versos da oitava 97 do Canto VI de $O s$ Lusiadas. Amainada a tempestade, graças à intervençáo da deusa do Amor, Vénus, o "Piloto Melindano" vislumbra à distância a "verdaira India." Perante notícia tão auspiciosa, Vasco da Gama ajoelha-se e dá graças a Deus por lhe mostrar a terra "Que com tanto temor buscando vinha / Por quem tanto trabalho esprimentava» (VI, 94). E é neste momento que o poeta, nas últimas cinco oitavas do Canto, tece solenemente consideraçôes ético-filosóficas sobre a maneira de alcançar o heroísmo, opondo a virtude da fortaleza ao pecado da preguiça. E é neste contexto que D. Francisco de Portugal, comparando-se com o Gama, transcreve os seis versos de Os Lusíadas. Comparando-se com o Gama e comparando-se com Camôes, pois facilmente se deduz do contexto que D. Francisco de Portugal atribui a Camóes o que este atribuira ao Gama. Razáo tem Helder Macedo para ver em Os Lusíadas, lado a lado com a viagem do argonauta - Vasco da Gama -, a viagem do poeta - Luís de Camôes ${ }^{17}$.

E por falar, em forma de metáfora, da "viagem iniciática" que foi para Camóes a escrita da sua epopeia, parece-nos, se nos é lícito parva componere magnis (comparar as coisas pequenas com as coisas grandes), que vai sendo tempo de pôr termo a esta nossa breve peregrinação por duas das três cartas de D. Francisco de Portugal, em busca dos versos de Camóes com que o seu autor quis embelezá-las e enriquecê-las e em busca do sentido patente e latente que se desprende desses versos. E, sendo assim, apenas repetiremos, para concluir, que em Camóes, no homem e no poeta, reconheceu D. Francisco de Portugal o melhor exemplo de homem duramente provado e injustamente açoitado e vitimado pelos golpes da fortuna e pela incompreensão e indiferença dos poderosos; que em Camóes encontrou o protótipo de moralista sábio e tolerante; e que em Camóes viu o "Mestre de Poetas Épicos".

${ }^{17}$ Helder Macedo, Camôes e a viagem iniciática. Lisboa: Moraes Editores, 1980. 